\title{
Does calcium channel blockade have a role in prevention of expression of sepsis in renal transplant recipients?
}

This article was published in the following Dove Press journal: International Journal of Nephrology and Renovascular Disease 23 November 2016

Number of times this article has been viewed

\author{
John A D’Elia ${ }^{1-3}$ \\ Ray E Gleason ${ }^{3}$ \\ Anthony P Monaco 2,3 \\ Larry A Weinrauch ${ }^{1-4}$ \\ 'Kidney and Hypertension \\ Section, Joslin Diabetes Center, \\ Boston, MA, ${ }^{2}$ Departments of \\ Surgery and Medicine, Beth Israel \\ Deaconess Medical Center, Boston, \\ MA, ${ }^{3}$ Harvard Medical School, \\ Boston MA, ${ }^{4}$ Department of \\ Medicine, Mount Auburn Hospital, \\ Cambridge, MA, USA
}

Correspondence: Larry A Weinrauch

52I Mount Auburn Street, Watertown,

MA 02472 USA

Tel + I 6179230800

Email lweinrauch@hms.harvard.edu

\begin{abstract}
Many antihypertensive agents have been demonstrated to assist in preservation of kidney function, among them those that modulate calcium channels. Calcium channel blockers may also be of value in protecting hemodialysis patients from complications of sepsis. In diabetic recipients of kidney transplant allografts treated with cyclosporine, calcium channel blockade has been retrospectively linked to improved graft preservation and to fewer episodes of sepsis. This brief review outlines clinical and experimental publications on potential protection from sepsis by addition of calcium channel blockers to standard antibiotic therapy in individuals who may or may not have normal kidney function, or in the presence or absence of immunosuppression. Such mechanisms include blockade of antibiotic cytosolic extrusion in the cases of Pneumococci, Mycobacterium tuberculosis, Plasmodium falciparum malaria, or Schistosoma mansoni; blockade of the calcineurin/calmodulin pathway (in immunosuppressed patients allowing for lower dosage of cyclosporine); stabilization of calcium movement at the level of sarcoplasmic reticulum by which shock (vasopressor instability) is prevented; or of cytosolic calcium influx and cell death (in the case of allograft acute tubular necrosis). Given the high cost of development of new antibiotics, a role for generic calcium channel blockade in sepsis prevention should be pursued by additional studies to investigate potential links between blockade of calcium channels and expression of sepsis in at-risk populations.
\end{abstract}

Keywords: renal transplant, transplantation sepsis, calcium channel blockade

\section{Introduction}

Initial enthusiasm for calcium channel blockers in renal transplantation related to their role in control of hypertension as well as the possibility that calcium channel blockers might be organ protective. Intracellular calcium infusion related cell death (as seen in the necrotic myocardium during acute coronary occlusion) has been shown in some early studies to be attenuated by calcium channel blockade of intracellular calcium entry through slow L channels. But concern for perioperative hypotension and acute kidney injury has been an impediment to the study of calcium channel blockers in renal transplant centers, particularly as the age of the target population has increased from less than 55 years to greater than 75 years.

Our interest in calcium channel blocker relates to patients with diabetic nephropathy requiring renal replacement therapy. Prolongation of kidney transplant recipient life as well as allograft function was noted to be significantly better in the presence of calcium channel blockade when compared to the use of other non-calcium channel blocker medications. ${ }^{1}$ In this brief report, we outline basic research and clinical observations 
that suggest a potential benefit for chronic calcium channel blockade with respect to protection from complications from sepsis in situations of uremia, immunosuppression, and malnutrition among diverse at-risk populations.

\section{Bacteremia and the development of sepsis}

Bacteremia at low levels has been noted to occur with common everyday activities. The normal response to such an invasion of the organism is the stimulation of the immune system to phagocytize the bacteria and create antibodies. Polymorphonuclear phagocytosis is controlled by calcium dependent channels affecting cytosolic calcium. In the immunosuppressed or frail patient, regulation of antibody control is confounded by immunosuppressive medications. To date, although potentiation of cyclosporine immunosuppression by calcium channel blockers has been demonstrated, there has been little attention to the role of these agents on the human organism response to bacteremia, or the vascular consequence of sepsis syndrome.

\section{Vasomotor control, calcium, and the sepsis syndrome}

Medium-sized blood vessels experience pulsatile flow as pressure is conveyed down to points of resistance and reflected backwards. Arterioles experience non-pulsatile constant flow, which can be increased with vasoconstriction or decreased with vasodilatation. Nitric oxide regulates arteriole flow, while calcium-activated potassium channels (along with nitric oxide) regulates conduit artery flow. ${ }^{2}$ Pathological concentrations of the vasoconstrictor, angiotensin, can cause damage to the muscular layer of larger blood vessels and to the endothelium of smaller blood vessels. ${ }^{3}$ The activation of an inflammation cascade inhibits expression of nitric oxide synthase; the loss of control of glucose disposal, which leads to oxidative stress, disrupts calcium/potassium vascular physiology; and the pressure-induced anatomical injury during uncontrolled hypertension results in loss of vascular integrity with impaired endothelial resistance to sepsis. ${ }^{4,5}$ These mechanisms are operative in chronic loss of kidney function through injury to blood vessels, interstitial matrix, and renal tubules, resulting in decreased production of 1,25 (OH)2 D (calcitriol). Since calcitriol has been shown to be additive to the inotropic effects of norepinephrine and vasopressin ${ }^{6}$ and receptors for 1,25 $(\mathrm{OH}) 2 \mathrm{D}$ are found in increased amounts in hypertrophied heart muscle, ${ }^{7}$ the fact that calcitriol synthesis in the proximal tubule decreases as kidney function is lost may be seen as protective from accelerated hypertension. There has been a long-standing debate concerning the intensity of replacement therapy for vitamin D deficiency in chronic renal insufficiency, especially since the possibility this active form of Vitamin D is protective from sepsis in certain experimental models. ${ }^{8-11}$ Several studies have addressed the use of dihydropyridine and nondihydropyridine calcium channel blockers in the perioperative period and in longer term follow-up, demonstrating improved allograft function ${ }^{12,13}$ that did not consistently appear to be secondary to blood pressure control. ${ }^{14,15}$ One study did demonstrate stable serum creatinine associated with a fall in renal vascular resistance calculated from mean arterial pressure and renal blood flow calculated from para-amino hippurate clearance. ${ }^{16}$ A fifth study found the occurrence of acute graft dysfunction (acute tubular necrosis) by biopsy to be significantly lower $(p<0.001)$ with verapamil vs a noncalcium channel group. ${ }^{17}$

\section{Mechanisms associated with prevention of sepsis}

Over 500,000 patients were listed as hypertensive in a survey of the United Kingdom General Practice database. ${ }^{18}$ The use of angiotensin converting enzyme inhibitors was associated with a significantly higher rate of hospitalization for sepsis as well as mortality at 30 days compared to use of angiotensin receptor blockers or calcium channel blockers. ${ }^{18}$ A retrospective cohort study of 387 patients admitted to hospital for pneumonia who were not being treated with calcium channel blockers, compared with 387 patients admitted to hospital who were treated with calcium channel blockers, revealed a significantly higher incidence of bacteremia, respiratory insufficiency, and transfer to intensive care unit for the non-treated group. ${ }^{19}$ A study of immunosuppressed recipients of kidney allografts from the pre-angiotensin receptor blocker era found a significantly higher incidence of sepsis with significantly shorter survivals of allograft function for 35 patients who had not received calcium channel blockers compared to 35 patients who did receive calcium channel blockers. ${ }^{20}$ Since the patients reviewed in studies of angiotensin-active medications and calcium channel blockers would have had hypertension, a precise mechanism for protection from sepsis would have to include protection from injury to blood vessels supplying skin, bronchus, and urinary bladder. Consequently, researchers developed other approaches. An experimental model for testing the impact of calcium channel blockers on sepsis involving ligation of the cecum with puncture of the wall of the intestine was one such example. This model demonstrated relatively longer survival 
if diltiazem were injected prior to the onset of septic shock ${ }^{21}$ in association with decreased formation of oxygen radicals. ${ }^{22}$

Specific calcium-related hypothetical mechanisms for protection from sepsis by calcium channel blockers include: (a) A decrease in cytosolic calcium of inflammation mediating cells, thereby limiting excessive cytokine responses, such as occurs in the adult respiratory distress syndrome; ${ }^{23}$ (b) an improved capacity to combat pathogens (chemotaxis, movement, adhesion, phagocytosis) through an increase in cytosolic calcium of polymorphonuclear cells and macrophages by release from intracellular stores (endoplasmic reticulum, sarcoplasmic reticulum, mitochondria) by homeostatic calcium movement by non-slow L channels; ${ }^{23}$ (c) an effect on invading pathogens to limit their capacity to select strains capable of rapid development of resistance to antibiotics. Calcium channel blockers have been studied in quinoloneresistant pneumococcal pneumonia ${ }^{24}$ rifampicin-resistant pulmonary tuberculosis, ${ }^{25}$ quinine-resistant Plasmodium falciparum malaria infestation, ${ }^{26,27}$ and praziquantel-resistant Schistosoma mansoni infestation. ${ }^{28,29}$ The mechanism does involve slow L channels blocking calcium entry from the exterior. The current understanding is the invading pathogen becomes drug-resistant by quickly extruding the medication followed by selection of progressively more resistant strains as doses are increased. Calcium channel blockers have been useful through blocking the alternate channel by which the antibiotic is extruded from its interior by the invading pathogen.

\section{Mechanisms associated with both beneficial and pathological responses to infection}

Studies of individuals under stress related to traumatic hemorrhage, hemodialysis, or uncontrolled diabetes provide insight into mechanisms of impaired host defenses. Hyperglycemic diabetic rats had polymorphonuclear neutrophils with marginal phagocytosis associated with elevated blood glucose by Seyrek et al, ${ }^{30}$ which subsequently showed this defect to be reversible with amlodipine in hemodialysis patients ${ }^{31}$ or with either glyburide or amlodipine in type 2 diabetic study subjects. ${ }^{32}$ The reversible cause of inhibited phagocytosis was an elevation of cytosolic calcium, which reverted to normal with blockade of intake at the slow L-type calcium channel in the cell wall. ${ }^{30}$ The measure of protection from infection noted in hemodialysis patients ${ }^{31}$ did not extend to hemodialysis catheter-related bacteremia. ${ }^{33}$ Simultaneously, the Hauser research group demonstrated that the predisposition of trauma patients to pneumonia ${ }^{34}$ with the accompanying inflammatory response syndrome (adult respiratory distress syndrome) could be reduced in the animal model with normalization of chemokine expression by use of calcium channel blockers. ${ }^{35}$

An increased prevalence of severe infections, most of which occur in the upper respiratory tract is noted in patients with low vitamin D levels with ${ }^{36}$ or without ${ }^{37,38}$ advanced kidney disease. Patients treated for sepsis in the intensive care setting may suffer the consequences of excessive inflammatory reaction as adult acute respiratory distress syndrome. ${ }^{23}$ While calcium channel blockers may decrease the complications of pneumonia by inhibiting inflammatory airway response, ${ }^{21-23}$ other systemic mechanisms may be just as important. In the murine cecal ligation/puncture sepsis model a depression of cardiac contractility associated with sepsis/bacteremia appears to be prevented by verapamil despite ongoing sepsis. ${ }^{39}$ The contribution of L-type calcium current to the action potential in septic ventricular myocytes has previously been demonstrated in pigs. ${ }^{40}$ This appears to occur at the level of the sarcoplasmic reticulum by blockade of calcium channel movement. ${ }^{41}$

\section{Proposals for future studies}

Sepsis syndrome is most likely to be expressed in the geriatric, infirm (recently hospitalized), or immunologically suppressed (those with diabetes, asplenism, hepatic or renal failure, AIDS, neoplasms, or undergoing immunosuppressive therapy) populations. Demonstration that chronic calcium channel blockade may attenuate expression of sepsis in high risk populations is, at the very least, intriguing. It is doubtful that a sponsor can be found to support a placebo-controlled trial for long-term calcium channel blockade for transplant recipients to determine the effect on all healthcare outcomes, including infectious and septic events. However, there do exist transplant registries and multicenter trial databases from which to glean additional information. An effort should be made to extract information where possible through the freedom of information act to determine if indeed there is any benefit or excess risk associated with the use of calcium channel blockers in the transplant population.

\section{Disclosure}

The authors have no conflicts of interest in this work.

\section{References}

1. Nanni G, Panocchia N, Tacchino R, Foco M, Piccioni E, Castagneto M Increased incidence of infection in verapamil-treated kidney transplant recipients. Transplant Proc. 2000;32:551-553.

2. Bellien J, Joannides R, Iacob M, Anaud P, Thuillez C. Calcium activated potassium channels and nitric oxide regulate human peripheral conduit artery mechanics. Hypertension. 2005;46:210-216. 
3. Doerschug KC, Delsing AS, Schmidt GA, Ashare A. Renin-angiotensin system activation correlates with microvascular dysfunction in a prospective cohort study of clinical sepsis. Crit Care. 2010;14(1):R24.

4. Lund DD, Brooks RM, Faraci FM, Heistad DD. Role of angiotensin II in endothelial dysfunction by lipopolysaccharide in mice. Am J Physiology Heart Circ Physiol. 2007:293(6):H3726-H3731.

5. Laesser M, Oi Y, Ewert J, Fandriks L, Aneman A. The angiotensin II receptor blocker candesartan improves survival and mesenteric perfusion in an acute porcine endotoxic model. Acta Anaethesiol Scand. 2004;48(2):198-204.

6. Bukoski RD, Xua H. On the vascular inotropic action of $1,25(\mathrm{OH})$ vitamin D3. Am J Hypertens. 1993;6:388-396.

7. Walthers MR, Wicker DC, Riggle PC. 1,25- dihydroxy D3 receptors identified in the rat heart. J Mol Cell Cardiol. 1986;18:67-72.

8. Horiuchi H, Nagata I, Komorlya K. Protective effect of vitamin D analogues on endotoxin shock in mice. Agents and Actions. 1991;33: 343-348.

9. Asakura H, Aoshima K, Suga Y, et al. Beneficial effect of the active form of vitamin D3 against LPS-induced DIC, but not against tissuefactor-induced DIC in rats. Thromb Haemost. 2001;85:287-290.

10. Liu PT, Stenger S, Li H, et al. Toll-like receptor triggering of a vitamin D-medicated human antimicrobial response. Science. 2008;311: $1770-1773$

11. Moller S, Laigaard F, Olgaard K, Hemmingsen C. Effect of 1,25-dihydroxy-vitaminD3 in experimental sepsis. Int J Med Sci. 2007;4:190-195.

12. Weir MR. Therapeutic benefits of calcium channel blockers in cyclosporine-treated organ transplant recipients: blood pressure control and immunosuppression. Am J Med. 1991;90:32S-36S

13. Chrystostomu A, Walker RG, Russ GR, D'Apice AJF, Kincaid-Smith I, Mathew TH. Diltiazem in renal allograft recipients receiving cyclosporine. Transplantation. 1993;55:300-304.

14. van Riemsdijk IC, Mulder P, deFijter JW, et al. Addition of isradipine (Lomir) results in better renal function after renal transplantation: a double blind randomized placebo controlled multicenter study. Transplantation. 2000;70:122-126.

15. Kuypers DR, Neumayer HH, Fritsche K, Rodicio JL, van Trentergen Y, Lacipine study group. Calcium channel blockade and preservation of renal graft function in cyclosporine-treated recipients: a prospective randomized placebo-controlled 2-year study. Transplantation. 2004;78:1204-1211.

16. Ahmed K, Michael B, Burk JF. Effects of isradipine on renal hemodynamics in renal transplant patients treated with cyclosporine. Clin Nephrol. 1997;48:307-310.

17. Jacobsson J, Odlind B, Tufveson G, Wahlberg J. Improvement of renal preservation by adding lidoflazine to University of Wisconsin solution. An experimental study in the rat. Cryobiology. 1992;29:305-309.

18. Dial S, Nessim SJ, Kezouh A, Benisty J, Suissa S. Antihypertensive agents acting on the renin-angiotensin system, and the risk of sepsis. Br J Clin Pharmacol. 2014;78:1151-1158.

19. Zeng L, Hunter K, Gaughan J, Podder S. Preadmission use of calcium channel blockers and outcomes after hospitalization with pneumonia: A retrospective propensity-matched cohort study. Am J Ther. 2015; August 13 [Epub ahead of print].

20. Weinrauch LA, D'Elia JA, Gleason RE, Shaffer D, Monaco AP. Role of calcium channel blockers in diabetic renal transplant patients: preliminary observations on protection from sepsis. Clin Nephrol. 1995;44:185-192

21. Meldrum DR, Ayala A, Chaudry IH. Mechanism of diltiazem's immunomodulatory effects after hemorrhage and resuscitation. Am J Physiol. 1993;265:C412-C421.

22. Rose S, Baumann H, Tahqeis GP, Sayeed MM. Diltiazem and superoxide dismutase modulate hepatic acute phase response in gram-negative sepsis. Shock 1994;1:87-93

23. Hotchkiss RS, Karl IE. Ca2+, a regulator of the inflammatory responsethe good, the bad, and the possibilities. Shock. 1997;7:308-310.
24. Pletz MW, Michaylov N, Schumacher U, et al. Antihypertensives suppress the emergence of flouroquinolone-resistant mutants in pneumococci: an in vitro study. Int J Med Microbiol. 2013; 303:P 176-181.

25. Song L, Cui R, Yang Y, Wu X. Role of calcium channels in cellular antituberculosis effects: Potential of voltage - gated calcium-channel blockers in tuberculosis therapy. J Microbiol Immunol Infect. 2015;48:471-476.

26. Scheibel LW, Colambani PM, Hess AD, Aikawa M, Atkinson T, Milhous WK. Calcium and calmodulin antagonists inhibit human malaria parasites (Plasmodium falciparum): implications for drug design. Proc Natl Acad Sci USA. 1987;84:7311-7314.

27. Martins YC, Clemmer L, Orjuela-Sanchez P, et al. Slow and continuous delivery of a low dose of nimodipine improves survival and electrocardiogram parameters in rescue therapy of mice with experimental cerebral malaria. Malar J. 2013;12:138-154.

28. Gryseels B, Mbaye A, DeVias SJ, et al. Are poor responses to praziquantel for treatment of Schistisoma mansoni infections in Senegal due to resistance? An overview of the evidence. Trop Med Int Health. 2001;6:864-873.

29. Silva-Moraes V, Couto FF, Vasconcelos MM, et al. Antischistosomal activity of a calcium channel antagonist on schistosomula and adult schistosoma Mansoni worms. Mem Inst Oswaldo Cruz. 2013;108: 600-604.

30. Seyrek N, Marcinkowski W, Smogorzewski M, Demerdash TM, Massry SG. Amlodipine prevents and reverses the elevation in [Ca2+]I and the impaired phagocytosis of PMNL of diabetic rats. Nephrol Dial Transplant. 1997;12:265-272.

31. Alexiewicz JM, Snogorzewski M, Klin M, Akmal M, Massry SG. Effective treatment of hemodialysis patients with nifedipine on metabolism and function of polymorphonuclear leukocytes. Am J Kidney Disease. 1995;25:440-444.

32. Krol E, Agueel R, Banue S, Smogorzewski M, Kumar D, Massry SG. Amlodipine reverses the elevation in $[\mathrm{Ca} 2+]$ and the impairment of phagocytosis in PMNLs of NIDDM patients. Kidney Int. 2003;64: 2188-2195.

33. Obialo CI, Conner AC, Lebon L. Calcium channel blockers do not prevent catheter associated infections in hemodialysis patients. Am J Hypertension. 2000;13(4 Part 2):123A-124A.

34. Tarlowe MH, Duffy A, Kannan KB, et al. Prospective study of neutrophil chemokine responses in trauma patients at risk for pneumonia. Am J Resp and Crit Care Med. 2005;171:753-759.

35. Lee C, Xu D-Z, Feketeova E, et al. Calcium entry inhibition during resuscitation from shock attenuates inflammatory lung injury. Shock. 2008;30:29-35.

36. Chonchol M, Greene T, Zhang Y, Hoofnagle AN, Cheung AK. Low vitamin D and high fibroblast growth factor 23 serum levels associate with infectious and cardiac deaths in the HEMO study. J Am Soc Nephrol. 2016;27:227-237.

37. Ginde AA, Mansbach JM, Carmargo CA Jr. Association between serum 25-hydroxyvitamin D level and upper respiratory tract infection in the Third National Health and Nutrition Examination Survey. Arch Int Med. 2009;169:384-390.

38. Laaksi I, Ruohola JP, Tuohimaa P, et al. An association of serum vitamin D concentrations $<40 \mathrm{nmol} / \mathrm{L}$ with acute respiratory tract infection in young Finnish men. Am J Clin Nutr. 2007;86:714-717.

39. Celes MR, Prado CM, Campos EC, et al. Calcium channel blocking drugs ameliorates the experimental septic cardiomyopathy induced by cecal ligation and puncture in mice. The FASEB Journal. 2012 Apr 1;26(1 Supplement):835-915.

40. Stengl M, Bartak, FI, Sykora R, et al. Reduced L-type calcium current in ventricular myocytes from pigs with hyperdynamic septic shock. Crit Care Med. 2010;38:579-587.

41. El-Awady MS, Smirnov SV, Watson ML. Voltage-independent calcium channels mediate lipopolysaccharide-induced hyporeactivity to endothelin-1 in the rat aorta. Am J Physiol Heart Circ Physiol. 2009;296: H1408-H-1415. 
The International Journal of Nephrology and Renovascular Disease is an international, peer-reviewed open access journal focusing on the pathophysiology of the kidney and vascular supply. Epidemiology, screening, diagnosis, and treatment interventions are covered as well as basic science, biochemical and immunological studies. The manuscript management system is completely online and includes a very quick and fair peer-review system, which is all easy to use. Visit http://www dovepress.com/testimonials.php to read real quotes from published authors.

Submit your manuscript here: https://www.dovepress.com/international-journal-of-nephrology-and-renovascular-disease-journal 